\title{
The Study on Credit Risk Warning of Regional Listed Companies in China Based on Logistic Model
}

\author{
Qingping Zhou, ${ }^{1,2}$ Long Wang, ${ }^{1}$ Li Juan, ${ }^{2}$ Shugong Zhou $\mathbb{D}^{2,3}$ and Lingli $\mathrm{Li}^{4}$ \\ ${ }^{1}$ Admission and Employment Office, Tangshan Normal University, Tangshan 063000, China \\ ${ }^{2}$ School of Mathematics and Computational Science, Tangshan Normal University, Tangshan 063000, China \\ ${ }^{3}$ Tangshan Key Laboratory of Agricultural Pathogenic Fungi and Toxins, Tangshan Normal University, Tangshan 063000,, China \\ ${ }^{4}$ College of Physics Science and Technology, Tangshan Normal University, Tangshan 063000, China
}

Correspondence should be addressed to Shugong Zhou; 281514017@qq.com

Received 19 December 2020; Accepted 22 April 2021; Published 5 May 2021

Academic Editor: Junhai Ma

Copyright (C) 2021 Qingping Zhou et al. This is an open access article distributed under the Creative Commons Attribution License, which permits unrestricted use, distribution, and reproduction in any medium, provided the original work is properly cited.

\begin{abstract}
The paper aims to propose a new method to state the credit risk characteristics of the regional listed companies in China and makes the listed companies avoid involving in credit crisis. The paper selects fifty-four listed companies of Hebei Province as the research sample and establishes the index system of listed company's credit risk evaluation from four financial index categories which included profitability, operating capacity, solvency, and growth capability. The paper first filtrates fifteen indexes by using the gray clustering method from the four financial categories and finds out the effective variables of the prediction model. Then the paper predicates the credit risk probability of the listed companies by using the logistic regression model. Finally, by analyzing the financial data of annual reports of fifty-four listed companies in Hebei Province from 2012 to 2017 as sample data, the simulation experiment empirical test is carried out by using SPSS software. The results show that the logistic regression model with gray clustering analysis has high predictive accuracy and has a strong predictive ability to evaluate the credit risk of listed companies. The gray logistics evaluation plays a very good role in financial early warning for regional listed companies in China.
\end{abstract}

\section{Introduction}

Credit risk of the listed companies is concerned by increasing investors and researchers. The researchers usually build a credit risk assessment model to avoid credit risk. There are four evaluation methods which are widely used [1]. The four methods include credit rating method, pluralistic statistic analysis method, dynamic measurement analysis method, and artificial intelligence like neural network method. However, the four methods have some defects. For example, the credit rating method is a subjective conjecture; therefore, the method is quite limited. The dynamic measurement analysis method can accurately describe the credit risk which is caused by the change of enterprise credit quality [2]. However, the stock market of China is not mature yet; the value of the stock market cannot reflect the real value of the enterprise. The defect of artificial intelligence method is that sometimes the method may get into local optimum and sometimes the method cannot get the optimal solution [3]. The pluralistic statistic analysis method is a traditional statics method. It mainly includes pluralistic discriminant analysis and logistic model analysis. The method is comparatively mature and widely used in many fields. The logistic model is adopted by many scholars. For example, a famous researcher named Tang Haiou has analyzed the financial indexes of 30 listed companies and verified the effectiveness of the Z-score model. Logistic model analysis establishes the logistic regression model by using the original data. This method is easy to operate. However, sometimes this method cannot get higher prediction accuracy [4].

Therefore, in this paper, the authors establish the logistic regression model of listed companies' credit risk and make use of the gray clustering method to estimate the parameters of the model. The logistic regression model is easy to operate 
and the gray clustering method can improve the prediction accuracy. The paper studies the credit risk of Chinese regional listed companies and their financial condition. Financial indexes are used as dependent variables to quantify the risk. The credit risk evaluation focuses on the debt repayment ability. The value of variables is divided into two types: "default" and "normal," corresponding to the companies with high credit risk and the companies with low credit risk [5]. Variables that the paper selects are binary variables, and the paper uses the logistic regression model to predicate the credit risk of the listed companies because this method is widely used in solving binary classification problems. As we know, if the company with higher risk is considered as a normal company, it will be more dangerous than the lower credit risk company which is considered as a higher credit risk company. Therefore, the paper can use 0.3 as the cut point to build the logistic regression model. The accuracy rate of the logistic regression model can reach $81.5 \%$. The paper uses logistic regression analysis as the main modeling method. To select model indexes, the gray correlation clustering method is used to simplify the index system of credit risk evaluation and can avoid multicollinear problems of explanatory variables [6]. Therefore, this paper combines the gray relational clustering method with the actual conditions of the credit risk model to select variables and constructs the logistic regression model. The paper also analyzes and assesses the credit risk of the listed companies in Hebei Province. It not only effectively reduces the multicollinear problems of explanatory variables but also ensures the explanatory maximum of variables [7].

\section{Methods}

\subsection{Building Models}

2.1.1. Standardization of Assessment Index. Assuming that the number of observation objects is $m, X=\left(X_{1}, X_{2}, \ldots\right.$, $\left.X_{n}\right)^{T}$ is an $n$-dimension random vector. $X$ is the financial index of the company. $n$ is the number of selected financial indexes. Due to the different value ranges or measurement units of the selected financial indexes, it is necessary to standardize the financial indexes. The common types of index attribute values can be divided into benefit index, cost index, and fixed index. The benefit index is the index that is the larger the better. The cost index is quite opposite. The fixed index is the index closer to a certain value, the better it is [8]. Generally, we can take the following methods to deal with these three types of indices:

The benefit index

$$
x_{i j}=\frac{x_{i}(j)-\min _{j}\left\{x_{i}(j)\right\}}{\max _{j}\left\{x_{i}(j)\right\}-\min _{j}\left\{x_{i}(j)\right\}} .
$$

The cost index

$$
x_{i j}=\frac{\max _{j}\left\{x_{i}(j)\right\}-x_{i}(j)}{\max _{j}\left\{x_{i}(j)\right\}-\min _{j}\left\{x_{i}(j)\right\}} .
$$

The fixed index

$$
x_{i j}=1-\frac{\left|x_{i}(j)-x_{i}^{\prime}(j)\right|}{\max _{j}\left|x_{i}(j)-x_{i}^{\prime}(j)\right|},
$$

where $x_{i}^{\prime}(j)$ is the optimal value of the fixed index $x(j)$

The standardized matrix $Y$ can be obtained by standardizing the original index values according to the above method.

$$
Y=\left[\begin{array}{cccc}
y_{1}(1) & y_{1}(2) & \cdots & y_{1}(m) \\
y_{2}(1) & y_{2}(2) & \cdots & y_{2}(m) \\
\vdots & \vdots & \cdots & \vdots \\
y_{n}(1) & y_{n}(2) & \cdots & y_{n}(m)
\end{array}\right]
$$

2.1.2. Gray Relational Cluster Analysis. The company's financial index is high relevance and multicollinearity. If the independent variables are not tackled, the predictive function of the logistic regression model will be greatly reduced [9]. Therefore, this paper uses the gray correlation clustering method to tackle the financial indexes of the company, to simplify the indexes, and to reduce their correlation and collinearity [10].

Gray relational clustering can calculate the correlation degree of each sample according to the gray theory and combine the similar factors by forming the correlation matrix of characteristic variables [11]. This paper uses the method of gray correlation clustering to cluster the selected financial indexes. Each cluster is regarded as a collection of a series of similar index variables. Financial indexes are reclassified by clustering and the most representative factor in each cluster is selected to represent this series. The gray clustering method not only ensures the adequacy of information but also reduces the multicollinearity problems between variables [12].

The standard matrix $Y$, for all $i \leq j, \quad i, j=1,2, \ldots, n$, calculates the absolute correlation degree $\varepsilon_{i j}$ of $\mathrm{Yi}$ and $\mathrm{Yj}$; thus, the triangular matrix $A$ is obtained.

$$
A=\left[\begin{array}{cccc}
\varepsilon_{11} & \varepsilon_{12} & \cdots & \varepsilon_{1 n} \\
& \varepsilon_{22} & \cdots & \varepsilon_{2 n} \\
& & \ddots & \vdots \\
& & & \varepsilon_{n n}
\end{array}\right]
$$

Here, $\varepsilon_{i i}=1, \quad i=1,2, \ldots, n$, is called the characteristic variable correlation matrix for matrix $A$.

If the critical value $R \in[0,1]$ is taken, it is generally required $R>0.5$. When $\varepsilon_{i j} \geq R, \mathrm{Yi}$ and $\mathrm{Yj}$ are merged into one class. The critical value affects the classification. Generally, the larger the $R$ value is, the closer to 1 it will be. The finer the cluster is, the fewer variables in the cluster group there will be. The smaller the value of $R$ is, the closer to 0 it will be and the coarser the cluster is, and there will be more variables in the cluster group. $R$ can be adjusted according to the actual needs and the correlation between the factors. Then we determine the final index variables to construct the logistic regression model. The method mentioned above has no requirement for sample size 
and is easy to operate. It can effectively overcome the problem of multicollinearity between variables [13].

2.1.3. Model Building. If we study the credit risk of a company, the value of the credit risk of the company can be regarded as a binary variable which is a random variable with $(0-1)$ distribution. Logistic regression is the most commonly used method to study these variables [14].

Suppose that the original data sequence of financial index variables of a listed company is $X_{i}=\left(x_{i}(1)\right.$, $\left.x_{i}(2), \ldots, x_{i}(n)\right)$; then $Y_{i}=\left(y_{i}(1), y_{i}(2), \ldots, y_{i}(n)\right)$ is the actual observation value [15]. The nonlinear relationship between the probability of credit risk which the model assumes and the variables of financial indexes will appear as follows:

$$
p\left(Y_{i}=1 \mid X_{i}\right)=F\left(Z_{i}\right)=\frac{1}{1+e^{-Z_{i}}} .
$$

By using the logit equation, (5) is transformed into a linear function:

$$
\log \text { it } P=\ln \left(\frac{p}{1-p}\right)=Z_{i}=\beta_{0}+\sum_{k=1}^{n} \beta_{k} x_{k i} \text {. }
$$

The financial index variables function as follows:

$$
Z_{i}=\beta_{0}+\sum_{k=1}^{n} \beta_{k} x_{k i}
$$

Equation (6) is the logistic function. Equation (7) is the linear combination of financial index variables that affect the probability of credit risk occurrence. $x_{i}$ is the explanatory variable. Parameter $\beta_{0}$ is a constant term. Parameter $\beta_{k}$ is a logistic regression coefficient. $n$ is the number of financial index variables. Usually, we use the iterative method to estimate the constant term and regression coefficient in the logistic function [16]. According to gray theory, we build a differential equation [17]:

$$
\frac{\mathrm{d} t^{(1)}}{\mathrm{d} x}+a x^{(1)}=u \text {. }
$$

The letter $a$ and the letter $u$ are called undetermined coefficients [18]. The interval value of $a$ is $(-2,2)$. We can obtain the matrix $a-u$, and the matrix is called gray parameter matrix. The matrix is $\widehat{a}=\left(\begin{array}{l}a \\ u\end{array}\right)$. By calculating the parameter $a$ and parameter $u$ [19], we can obtain the forecasting value $x^{(0)}$. Then the paper carried out the accuracy test of the gray model. The residual error test is carried out. The residual error function is as follows:

$$
E(k)=x^{(0)}(k)-x^{(0)}(k) .
$$

The variance of residual error is described as follows:

$$
\bar{E}=\frac{1}{n-1} \sum_{k=2}^{n} E(k) \text {. }
$$

The mean value of residual error is described as follows:

$$
S_{2}=\sqrt{\frac{1}{n-1} \sum_{k=2}^{n}[E(k)-\bar{E}]^{2} .}
$$

\subsection{Empirical Analysis}

2.2.1. Sample Selection and Index Selection. From 2012 to 2017, there are 56 listed companies in Hebei Province; one of them is an ST company. To ensure the comparability of the samples, Fangzhan, which is ST company, is removed. Due to the particularity of financial indexes of financial enterprises, Baoshuo shares were also removed. Therefore, the samples of this paper are 54 listed companies in Hebei A-share market from 2012 to 2017. These 54 companies belong to 18 different industries in the industry classification by China Securities Regulatory Commission, and they have strong industrial representation [20]. The 18 industries are numbered as follows

A1: coal industry, A2: food manufacturing industry, A3: liquor and beverage manufacturing industry, A4: metallurgical industry, A5: cement manufacturing industry, A6: chemical industry, A7: furniture manufacturing industry, A8: textile industry, A9: leather, fur, feather, and their products, A10: pharmaceutical industry, A11: mechanical industry, A12: electronic industry, A13: thermal power generation industry, A14: water transportation industry, A15: information technology service industry, A16: wholesale and retail trade industry, A17: real estate industry, and A18: livestock industry. Taking these 18 industry classifications as observation objects, each observation object has 15 characteristic data, which come from financial indexes that affect the credit risk of listed companies [21].

This paper selects 15 financial indexes as candidate variables from the four financial indexes of profitability, operating capacity, solvency, and growth capability. The data of financial indexes are from the annual reports of listed companies of various industries [22]. Financial indexes are selected as follows, as shown in Table 1.

2.2.2. Variable Processing. Based on the above-mentioned sample data and relevant data of financial indexes, the average value of each industry index is used as the basis of gray clustering analysis [23] (see Table 2 for detailed data). The gray clustering analysis of data is carried out using gray modeling software which is called Gray Modeling (version 3.0).

The relevance matrix of characteristic variables is obtained as shown in Table 3.

In this paper, the critical value of 0.85 is taken as the basis of classification. The critical value not only ensures the sufficiency of information but also simplifies the indexes [24]. These 15 financial indexes are grouped into eight categories. $X 1, X 3$, and $X 15$ are grouped into one category; $X 2, X 6$, and $X 10$ are grouped into one category; $X 5$ and $X 14$ are grouped into one category; $X 7$ and $X 11$ are grouped into one category; X8 and X12 are grouped into another category; 
TABLE 1: Index and definitions.

\begin{tabular}{|c|c|c|c|}
\hline Index type & & Index name & Definition \\
\hline \multirow{5}{*}{ Profitability } & $\mathrm{X}_{1}$ & Return on net assets & Net profit/net assets \\
\hline & $X_{2}$ & Return on total assets & EBIT/total assets \\
\hline & $X_{3}$ & Operating profit margin & Operating profit/total business income \\
\hline & $X_{4}$ & Cost profit margin & Operating profit/total cost \\
\hline & $X_{5}$ & Turnover rate of total assets & Operating income/average total assets \\
\hline \multirow{3}{*}{$\begin{array}{l}\text { Operating } \\
\text { capacity }\end{array}$} & $X_{6}$ & $\begin{array}{c}\text { Turnover rate of accounts } \\
\text { receivable }\end{array}$ & Operating income/average accounts receivable \\
\hline & $X_{7}$ & Inventory turnover ratio & Operating cost/average inventory \\
\hline & $X_{8}$ & Turnover rate of circulating assets & Operating income/average circulating assets \\
\hline \multirow{4}{*}{ Solvency } & $X_{9}$ & Asset liability ratio & Total liabilities/total assets \\
\hline & $X_{10}$ & Earned interest multiple & Earning before interest and tax/interest expense \\
\hline & $X_{11}$ & Quick ratio & Quick assets/current liabilities \\
\hline & $X_{12}$ & Cash flow liability ratio & Net cash flow/current liabilities \\
\hline \multirow{3}{*}{ Growth ability } & $X_{13}$ & Growth rate of operating revenue & Growth of operating revenue in that year/operating income of last year \\
\hline & $X_{14}$ & Operating profit growth rate & Increase in operating profit of that year/operating profit of last year \\
\hline & $X_{15}$ & Growth rate of total assets & Growth of total assets in that year/total assets at the beginning of the period \\
\hline
\end{tabular}

TABLE 2: Financial index data of various industries.

\begin{tabular}{|c|c|c|c|c|c|c|c|c|c|}
\hline & $A_{1}$ & $A_{2}$ & $A_{3}$ & $A_{4}$ & $A_{5}$ & $A_{6}$ & $A_{7}$ & $A_{8}$ & $A_{9}$ \\
\hline$X_{1}$ & 1 & 4.1 & 7.5 & -3 & 5.1 & 1.8 & 1.8 & 2.4 & 6.6 \\
\hline$X_{2}$ & 1.2 & 3.3 & 7.2 & 0.3 & 4.1 & 1.4 & 1.3 & 2.3 & 5.5 \\
\hline$X_{3}$ & 9.6 & 12 & 22.2 & 2 & 12 & 8.8 & 11 & 7.8 & 11 \\
\hline$X_{4}$ & 0.9 & 4.8 & 9.2 & -2.6 & 9.9 & 0.8 & 4.7 & 1.5 & 4.8 \\
\hline$X_{5}$ & 0.3 & 0.6 & 0.7 & 0.5 & 0.7 & 0.5 & 0.6 & 0.7 & 1 \\
\hline$X_{6}$ & 3.5 & 5.3 & 12 & 98 & 13 & 6.2 & 5 & 11 & 9 \\
\hline$X_{7}$ & 7.5 & 3.3 & 3.3 & 4.5 & 7.2 & 6.3 & 2.6 & 4.7 & 4.5 \\
\hline$X_{8}$ & 1.1 & 2.1 & 1.2 & 1.6 & 1.8 & 1.6 & 0.9 & 1.4 & 1.9 \\
\hline$X_{9}$ & 60 & 60 & 60 & 60 & 60 & 60 & 60 & 60 & 60 \\
\hline$X_{10}$ & 0.9 & 2.9 & 4.6 & 0.4 & 2.6 & 0.5 & 3.6 & 1.7 & 5.8 \\
\hline$X_{11}$ & 76.6 & 87 & 85.7 & 50 & 60.4 & 72 & 84.3 & 75.3 & 85.4 \\
\hline$X_{12}$ & 5.6 & 5.5 & 12.8 & 2.6 & 9.4 & 8 & 4.9 & 5.3 & 5.9 \\
\hline$X_{13}$ & -35.5 & 5.4 & 4.7 & -15 & 7.6 & 0.9 & 9.9 & 3.7 & 2.1 \\
\hline$X_{14}$ & -30.6 & 8.5 & 5.9 & -20 & -7.9 & 7 & 2.9 & 1.5 & 1.9 \\
\hline$X_{15}$ & 4.5 & 2.2 & 7.8 & 6.7 & 12.4 & 3.5 & 3.8 & 3.5 & 3.6 \\
\hline & $A_{10}$ & $A_{11}$ & $A_{12}$ & $A_{13}$ & $A_{14}$ & $A_{15}$ & $A_{16}$ & $A_{17}$ & $A_{18}$ \\
\hline$X_{1}$ & 9.9 & 3 & 3.4 & 4.2 & 1.4 & 4.2 & 3.6 & 5 & 5.7 \\
\hline$X_{2}$ & 8.5 & 2.3 & 2.1 & 3.5 & 0.9 & 2.5 & 2.8 & 2.5 & 2.8 \\
\hline$X_{3}$ & 27 & 12.1 & 7.9 & 13.5 & 3.5 & 14 & 2.2 & 15 & 11 \\
\hline$X_{4}$ & 9 & 4.9 & 2.9 & 4.8 & 3.7 & 6.2 & 1.1 & 10 & 4 \\
\hline$X_{5}$ & 0.5 & 0.3 & 0.6 & 0.3 & 0.4 & 1 & 0.6 & 0.3 & 0.8 \\
\hline$X_{6}$ & 5.6 & 3.1 & 2 & 8 & 6.5 & 5.6 & 6.5 & 5 & 8.1 \\
\hline$X_{7}$ & 3.3 & 3.5 & 2.3 & 11.2 & 9.3 & 14 & 7 & 0.5 & 4.8 \\
\hline$X_{8}$ & 1.5 & 1 & 0.9 & 1.2 & 1.2 & 2.5 & 1.1 & 0.3 & 1.7 \\
\hline$X_{9}$ & 60 & 60 & 60 & 72.5 & 65 & 65 & 65 & 70 & 65 \\
\hline$X_{10}$ & 3.5 & 2.3 & 1.5 & 1.1 & 2.2 & 3.2 & 1.2 & 2.5 & 1.8 \\
\hline$X_{11}$ & 81 & 78.2 & 98 & 30.1 & 97 & 83 & 77 & 65 & 66 \\
\hline$X_{12}$ & 8.8 & 2.1 & 3.4 & 10.8 & 5.9 & 34 & 2.2 & 1 & 4 \\
\hline$X_{13}$ & 9.8 & 0.1 & 5 & -9.3 & 1.9 & 1.2 & 1.5 & 1 & 8.8 \\
\hline$X_{14}$ & 8 & 0.1 & 5 & 1.2 & 1.8 & -5.8 & 1 & -2 & -1.1 \\
\hline$X_{15}$ & 9.6 & 7 & 4.5 & 2.1 & 2.6 & 4.7 & 3 & 8 & 2.2 \\
\hline
\end{tabular}

and each of the other three indexes $X 4, X 9$, and $X 13$ is classified into one category separately. Finally, this paper selects the eight financial indexes $X 1, X 2, X 4, X 5, X 7, X 9$, $X 12$, and X13 for modeling.
2.2.3. Modeling. Logistic model samples include unhealthy companies and healthy companies [25]. Most scholars regard those listed companies which have been specially treated $\left(\mathrm{ST} ;{ }^{*} \mathrm{ST}\right)$ as unhealthy companies; the others are 
TABLE 3: Correlation matrix of financial indexes.

\begin{tabular}{|c|c|c|c|c|c|c|c|c|c|c|c|c|c|c|c|}
\hline & $X_{1}$ & $X_{2}$ & $X_{3}$ & $X_{4}$ & $X_{5}$ & $X_{6}$ & $X_{7}$ & $X_{8}$ & $X_{9}$ & $X_{10}$ & $X_{11}$ & $X_{12}$ & $X_{13}$ & $X_{14}$ & $X_{15}$ \\
\hline$X_{1}$ & 1.00 & 0.56 & 0.85 & 0.608 & 0.542 & 0.563 & 0.658 & 0.769 & 0.647 & 0.568 & 0.68 & 0.762 & 0.51 & 0.546 & 0.92 \\
\hline$X_{2}$ & & 1.000 & 0.556 & 0.716 & 0.769 & 0.961 & 0.536 & 0.586 & 0.599 & 0.979 & 0.5 & 0.584 & 0.562 & 0.724 & 0.56 \\
\hline$X_{3}$ & & & 1.000 & 0.583 & 0.5 & 0.558 & 0.726 & 0.690 & 0.60 & 0.558 & 0.76 & 0.687 & 0.511 & 0.533 & 0.920 \\
\hline$X_{4}$ & & & & 1.000 & 0.616 & 0.699 & 0.542 & 0.664 & 0.72 & 0.725 & 0.549 & 0.666 & 0.527 & 0.596 & 0.6 \\
\hline$X_{5}$ & & & & & 1.000 & 0.791 & 0.526 & 0.548 & 0.55 & 0.768 & 0.528 & 0.548 & 0.616 & 0.916 & 0.54 \\
\hline$X_{6}$ & & & & & & 1.000 & 0.533 & 0.578 & 0.59 & 0.962 & 0.53 & 0.57 & 0.568 & 0.742 & 0.558 \\
\hline$X_{7}$ & & & & & & & 1.000 & 0.585 & 0.54 & 0.534 & 0.929 & 0.583 & 0.510 & 0.526 & 0.688 \\
\hline$X_{8}$ & & & & & & & & 1.000 & 0.76 & 0.589 & 0.601 & 0.987 & 0.512 & 0.561 & 0.72 \\
\hline$X_{9}$ & & & & & & & & & 1.000 & 0.601 & 0.555 & 0.780 & 0.512 & 0.543 & 0.624 \\
\hline$X_{10}$ & & & & & & & & & & 1.000 & 0.538 & 0.588 & 0.560 & 0.716 & 0.563 \\
\hline$X_{11}$ & & & & & & & & & & & 1.000 & 0.598 & 0.510 & 0.526 & 0.723 \\
\hline$X_{12}$ & & & & & & & & & & & & 1.000 & 0.5 & 0.5 & 0.720 \\
\hline$X_{13}$ & & & & & & & & & & & & & 1.000 & 0.639 & 0.511 \\
\hline$X_{14}$ & & & & & & & & & & & & & & 1.000 & 0.53 \\
\hline$X_{15}$ & & & & & & & & & & & & & & & 1.00 \\
\hline
\end{tabular}

healthy companies. However, this classification method is not suitable for regional listed companies with little sample data. Therefore, we cannot take those as grouping indices by whether the listed companies are specially treated or not [26]. We should put into consideration comprehensively all aspects of the financial conditions of listed companies.

The occurrence of the credit risk of listed companies is related to the financial condition of the enterprises [27]. Therefore, this paper believes that if half or more of the financial indexes of listed companies show signs of deterioration while being compared with the industry average, the company will have credit risk. If the company has credit risk, that is unhealthy, the value is 1 ; if there is no credit risk, that is, "healthy," the value is 0 [28].

In the logistic model, the choice of cutting point has a great influence on the result of the model [29]. In practical application, the value of cutting point and the misjudgment rate of unhealthy companies meet the increasing relationship [30]. This means that the larger the value of the cutting point is, the higher the rate of misjudgment will be. Generally speaking, it is not very dangerous that a healthy company is misjudged as an unhealthy company. However, it seems more dangerous that a company which has higher credit risk is considered as a healthy company. Therefore, this paper takes the above considerations and finally selects 0.3 as the cutting point to construct the logistic model [31].

By using SPSS software, using maximum likelihood estimation, logistic regression analysis was carried out on the above 8 variables by forward stepwise regression method [32]. The output results that come from SPSS software are shown in Table 4. Finally, two variables get into the model: return on total asset ratio $X 2$ and growth rate of operating revenue $X 13$. If the significant values of $X 2$ and $X 13$ are less than 0.05 , this shows that the two variables have good statistical characteristics, and the variables were significant.

To assess the fitting effect of the model to the data, it is necessary to test $\mathrm{H}-\mathrm{L}$ fitting degree of the model. The test results are shown in Table 5

When the significance level is 0.05 and $\mathrm{df}=8$, the critical value of chi-square is 15.507 . The chi-square value of $\mathrm{H}-\mathrm{L}$
TABLE 4: Final variables.

\begin{tabular}{lccccc}
\hline & $B$ & S.E. & Wald & Sig. & Exp $(B)$ \\
\hline$X_{2}$ & -0.128 & 0.05 & 6.453 & 0.011 & 0.880 \\
$X_{13}$ & -0.086 & 0.02 & 8.232 & 0.004 & 0.92 \\
Constant & 1.886 & 1.068 & 3.233 & 0.072 & 6.58 \\
\hline
\end{tabular}

TABle 5: The H-L test table.

\begin{tabular}{lcc}
\hline Chi-square & df & Sig. \\
\hline 6.01 & 8 & 0.641 \\
\hline
\end{tabular}

was $6.061<15.507$, significant value $0.64>0.05$. According to this, it can be concluded that the $\mathrm{H}-\mathrm{L}$ test can pass and the model can fit the data well [33]. Therefore, the logistic function can be obtained.

$$
\ln \left(\frac{p}{1-p}\right)=\xi+\sum_{k=1}^{m} \beta_{k} x_{k i}=1.884-0.127 X_{2}-0.084 X_{13}
$$

The default warning model is

$$
p=\frac{1}{1+e^{-\left(1.884-0.127 X_{2}-0.084 X_{13}\right)}} .
$$

Given the company's $X 2$ and $X 13$ data, we can calculate the probability of default of the company. The results of the accuracy test of the model are as shown in Table 6.

2.2.4. Empirical Test. To further test the effectiveness of the Logistic Default early warning model based on gray relational cluster analysis [34], this paper randomly selects 8 healthy companies and 8 unhealthy companies for the empirical test (the data come from the annual report of Hebei listed companies in 2017 made by Ruisi Database) [35]. The default probability can be calculated by taking the financial data of the 16 enterprises into equation (7). The test results are shown in Table 7. 
TABLE 6: Classification table.

\begin{tabular}{|c|c|c|c|c|}
\hline \multirow{3}{*}{ Observation } & \multicolumn{4}{|c|}{ Prediction } \\
\hline & & \multicolumn{2}{|c|}{ Default or not } & \multirow[t]{2}{*}{ Percentage of correctness } \\
\hline & & 0 & 1 & \\
\hline \multirow{2}{*}{ Default or not } & 0 & 34 & 6 & $85 \%$ \\
\hline & 1 & 4 & 10 & $71.4 \%$ \\
\hline Overall percentage & & & $81.5 \%$ & \\
\hline
\end{tabular}

TABLe 7: Results of logistic model data test.

\begin{tabular}{|c|c|c|c|c|c|}
\hline Name of the company & $X_{2}$ & $X_{13}$ & $P$-value & Observed value & Predictive value \\
\hline Changshan BeiMing & 8.6372 & 2.52 & 0.63356 & 0 & 1 \\
\hline Jidong Cement & 37.12 & 23.9526 & 0.0079 & 0 & 0 \\
\hline Jidong Equipment & 3.667 & 64.6809 & 0.0179 & 0 & 0 \\
\hline Ziguangguowei & 15.1804 & 28.9392 & 0.0690 & 0 & 0 \\
\hline Bosun Tools & 15.1306 & 32.687 & 0.0399 & 0 & 0 \\
\hline Sailhero Environment Protection & 13.78 & 32.0431 & 0.0719 & 0 & 0 \\
\hline Changshan Pharmaceutical & 10.169 & 26.9899 & 0.1576 & 0 & 0 \\
\hline Kailuan Co. Ltd. & 33.726 & 58.2568 & 0.0007 & 0 & 0 \\
\hline Tianye Tonglian & 15.1992 & 11.5804 & 0.2826 & 1 & 0 \\
\hline Huasi Co. Ltd. & 3.0712 & 26.3622 & 0.3276 & 1 & 1 \\
\hline Jikai Co. Ltd. & 9.7626 & 78.5319 & 0.0029 & 1 & 0 \\
\hline Hengxin Dongfang & 7.5616 & 1.7748 & 0.6845 & 1 & 1 \\
\hline Laobaigan Liquor & 17.9349 & 3.9631 & 0.3259 & 1 & 1 \\
\hline North China Pharmaceutical & 20.008 & -4.6193 & 0.4332 & 1 & 1 \\
\hline Fucheng Co. Ltd. & 17.436 & -0.7616 & 0.4337 & 1 & 1 \\
\hline Pangda Group & 5.2019 & 6.7806 & 0.6579 & 1 & 1 \\
\hline
\end{tabular}

Table 8: Accuracy of logistics model.

\begin{tabular}{lcccc}
\hline \multirow{2}{*}{ Original result } & & \multicolumn{3}{c}{ Prediction result } \\
& & Default & Normal & Accuracy \\
\hline \multirow{2}{*}{ Type of enterprise } & Default & 6 & 2 & $75 \%$ \\
& Normal & 1 & 7 & $87.5 \%$ \\
\hline Overall percentage & & \multicolumn{4}{c}{$81.25 \%$} \\
\hline
\end{tabular}

\section{Results and Discussion}

From the data analysis, we found that two indicators which are the return on total asset ratio and growth rate of operating revenue play an essential role in credit risk evaluation of the listed companies. The two indicators are a positive correlation with the credit status of the listed companies [36]. In the research of the regional listed companies of Hebei Province, we use all the sample data for the parameter estimation of the model because of the small number of sample data. Then, we achieve the prediction value of all sample data and check the prediction effect according to the accuracy rate and misjudgment ratio [37]. According to Table 6, the comprehensive classification accuracy rate of the logistic model is $81.5 \%$. The classification accuracy rate of healthy companies is $85 \%$. The classification accuracy rate of unhealthy companies is $71.4 \%$. Therefore, the model has good prediction ability [38].

From Table 8, we can see that the prediction accuracy of the credit risk assessment model of listed companies in Hebei Province (which was established by logistic regression method) reaches $81.25 \%$, and the probability of misjudgment is $18.75 \%$. The prediction result is relatively satisfactory [39].

\section{Conclusions}

This paper uses gray cluster analysis to cluster the financial indexes of the selected listed companies to achieve the effect of index reduction and reduce the correlation between the indexes. And it is guaranteed that the financial index information is not damaged. Logistic regression analysis is used to construct the credit risk assessment model for the reduced indexes, which can reduce the workload of collecting invalid data. The empirical research results show that the model has strong prediction ability and accuracy for assessing the credit risk of listed companies in China. It can play an early warning role of the credit risk of listed companies.

\section{Data Availability}

The data used to support the findings of this study are available from the corresponding author upon request.

\section{Conflicts of Interest}

The authors declare that there are no conflicts of interest regarding the publication of this paper.

\section{Acknowledgments}

This research was supported by the Science \& Technology Research Project of Colleges and Universities in Hebei Province, Grant no. ZD2020403; Scientific Research Project of Tangshan Normal University, Grant no. 2020A13; and 
Natural Science Foundation of Hebei Province, Grant no. A2019105110.

\section{References}

[1] D. Garcia, "Leaking privacy and shadow profifiles in online social networks," Science Advances, vol. 3, Article ID e1701172, 2017.

[2] H. Y. Wu, "Research on the deelopment model and spatial distribution pattern of rural tourism in Chongqing based on accurate poverty alleviation," Chinese Journal of Agricultural Resources and Regional Planning, vol. 40, no. 10, pp. 244-249, 2019.

[3] Z. Xie and J. Yan, "Kernel Density Estimation of traffic accidents in a network space," Computers, Environment and Urban Systems, vol. 32, no. 5, pp. 396-406, 2008.

[4] C. Li and X. Ji, "Innovation, licensing, and price vs. quantity competition," Economic Modelling, vol. 27, no. 3, pp. 746-754, 2010.

[5] A. T. Shen and A. Volodin, "Weak and strong laws of large numbers for arrays of rowwise END random variables and their applications," Metrika, vol. 80, no. 2, pp. 1-21, 2017.

[6] Y. Huang and Z. Wang, "Information sharing in a closed-loop supply chain with learning effffect and technology licensing," Journal of Cleaner Production, vol. 271, Article ID 122544, 2020.

[7] Y. Huang and Z. Wang, "Pricing and production decisions in a closed-loop supply chain considering strategic consumers and technology licensing," International Journal of Production Research, vol. 57, no. 9, pp. 2847-2866, 2019.

[8] C.-H. Wu and Y.-J. Kao, "Cooperation regarding technology development in a closed-loop supply chain," European Journal of Operational Research, vol. 267, no. 2, pp. 523-539, 2018.

[9] X. L. Wan and X. Q. Qie, "Poverty alleviation ecosystem evolutionary game on smart supply chain platform under the government fifinancial platform incentive mechanism," Journal of Computational and Applied Mathematics, vol. 372, Article ID 112595, 2020.

[10] J. Ma and L. Sun, "Complexity analysis about nonlinear mixed oligopolies game based on production cooperation," IEEE Transactions on Control System Technology, no. 26, pp. 1532-1539, 2018.

[11] J. Gao, Z. Li, T. Wu, and L. Wang, "Diversity of contribution promotes cooperation in public goods games," Physica A: Statistical Mechanics and Its Applications, vol. 389, no. 16, pp. 3166-3171, 2010.

[12] P. De Giovanni, P. V. Reddy, and G. Zaccour, "Incentive strategies for an optimal recovery program in a closed-loop supply chain," European Journal of Operational Research, vol. 249, no. 2, pp. 605-617, 2016.

[13] Ma Junhai, H. Yaming, and Y. Wenhui, "Pricing strategy and coordination of automobile manufacturers based on government intervention and carbon emission reduction," Energy Policy, vol. 148, p. 1, Article ID 111919, 2021.

[14] I. D. Couzin and J. Krause, "Self-organization and collective behavior in vertebrates," Advances in theStudy of Behavior, vol. 32, no. 1, 2003.

[15] Q. Qin, Z. L. Hu, A. L. Liu, Y. Huang, and F. Zhang, "Identifification and evolution of the noncoordination coupling relationship between tourism poverty alleviation and ecological environments in poor mountainous areas," Discrete Dynamics in Nature and Society, vol. 2020, Article ID 5094863, 14 pages, 2020.
[16] R. Yu, J. Cai, and P. Leung, "The normalized revealed comparative advantage index," The Annals of Regional Science, vol. 43, no. 1, pp. 267-282, 2009.

[17] X. Zhang, China's Trade Patterns and International Comparative Advantage, Palgrave Macmillan, London, UK, 2000.

[18] A. Ghosh and S. Saha, "Price competition, technology licensing and strategic trade policy," Economic Modelling, vol. 46, pp. 91-99, 2015.

[19] S. Wang, J. Fan, D. Zhao, and S. Wang, "Regional innovation environment and innovation efficiency: the Chinese case," Technology Analysis \& Strategic Management, vol. 28, no. 4, pp. 396-410, 2016.

[20] M. Gao, F. Hu, J. Sun, and Z. Zong, "A strong law of large number for negatively dependent and non identical distributed random variables in the framework of sublinear expectation," Communications in Statistics-Theory and Methods, vol. 4820 pages, 2019.

[21] Q. Wu and Y. Jiang, "Strong law of large numbers and Chover's law of the iterated logarithm under sub-linear expectations," Journal of Mathematical Analysis and Applications, vol. 460, no. 1, pp. 252-270, 2018.

[22] U. Khalid and Z. Liu, "Innovation index framework to measure the innovation capacity and efficiency of SAARC countries," European Journal of Social Sciences, vol. 46, no. 3 , pp. 325-338, 2015.

[23] D. Aigner, C. A. K. Lovell, and P. Schmidt, "Formulation and estimation of stochastic frontier production function models," Journal of Econometrics, vol. 6, no. 1, pp. 21-37, 1977.

[24] J. P. LaSalle, Be Stability of Dynamical Systems, Regional Conference Series in Applied Mathematics, SIAM, Philadelphia, PA, USA, 1976.

[25] R. H. Martin, "Logarithmic norms and projections applied to linear differential systems," Journal of Mathematical Analysis and Applications, vol. 45, no. 2, pp. 432-454, 1974.

[26] A. M. Davis, "A simple way of obtaining the reduced Jordan form of a state equation," IEEE Transactions on Education, vol. 47, no. 4, pp. 481-489, 2004.

[27] S. Yin and L. Chen, "Technological innovation effiffifficiency of Chinese pharmaceutical fifirms based on two-phase SFA study," Soft Science, vol. 30, no. 5, pp. 54-58, 2016.

[28] C. T. Chen, Digital Signal Processing, Oxford University Press, New York, NY, USA, 2001.

[29] R. C. Robinson, An Introduction to Dynamical System: Continuous and Discrete, Prentice-Hall, Upper Saddle River, NJ, USA, 2004.

[30] S. Meloni, C.-Y. Xia, and Y. Moreno, "Heterogeneous resource allocation can change social hierarchy in public goods games," Royal Society Open Science, vol. 4, no. 3, p. 170092, 2017.

[31] B. Bao, J. Ma, and M. Goh, "Short- and long-term repeated game behaviours of two parallel supply chains based on government subsidy in the vehicle market," International Journal of Production Research, vol. 12, no. 58, pp. 7507-7530, 2020.

[32] F. Si and J. Ma, "Complex dynamics in a triopoly game with multiple delays in the competition of green product level," International Journal of Bifurcation and Chaos, vol. 28, no. 2, Article ID 1850027, 2018.

[33] L. Xie, J. Ma, and M. Goh, "Supply chain coordination in the presence of uncertain yield and demand," IInternational Journal of Production Research, vol. 5, 2020.

[34] X. Su and H. Zhang, "Research on the governance of agricultural product channel relations from the perspective of 
tripartite game," Journal of Agro-Technical Economics, no. 3, pp. 42-52, 2017.

[35] X. Su, S. Duan, S. Guo, and H. Liu, "Evolutionary games in the agricultural product quality and safety information system: A multiagent simulation approach," Complexity, vol. 2018, Article ID 7684185, 13 pages, 2018.

[36] H. I. Freedman, S. Ruan, and M. Tang, "Uniform persistence and flows near a closed positively invariant set," Journal of Dynamics and Differential Equations, vol. 6, no. 4, pp. 583600, 1994.

[37] W. M. Hauser and R. T. Lund, Remanufacturing: Operating Practices and Strategies: Perspectives on the Management of Remanufacturing Businesses in the united states, Department of Manufacturing Engineering Boston University, Boston, MA, USA, 2008.

[38] L. Xie, J. Ma, and H. Han, "Implications of stochastic demand and manufacturers' operational mode on retailer's mixed bundling strategy and its complexity analysis," Applied Mathematical Modelling, vol. 55, no. 55, pp. 484-501, 2018.

[39] X. Su, H. Liu, and S. Hou, "The trilateral evolutionary game of agri-food quality in farmer-supermarket direct purchase: a simulation approach," Complexity, vol. 2018p. 11, Article ID 5185497, d, 2018. 